\title{
Peer support for eating disorders: a pilot open trial of peer support for children and adolescents with eating disorders
}

\author{
Stephanie Wade ${ }^{1 *}$, Hunna Watson², Jemma Caswell ${ }^{3}$, Julie Purcell ${ }^{2}$ \\ From 2014 ANZAED Conference: Driven Bodies Driven Brains \\ Fremantle, Australia. 22-23 August 2014
}

The current pilot study aimed to evaluate the effectiveness of a brief peer support intervention for adolescents with eating disorders, run within an established specialist hospital service. Peers are defined in this context to reflect individuals who have experienced overcoming an eating disorder. The peer support intervention was designed to run concurrently with the hospital program, with focus on removing the additional barriers to recovery, such as low motivation for recovery, that are not specifically targeted by traditional health systems. Participant groups of inpatients, day-patients and outpatients each attended two structured group sessions, and completed pre- and post-group questionnaires. Quantitative and qualitative analyses comparing pre- to post-group ratings revealed a significant decrease in participant's feelings of stigma associated with having an eating disorder; a significant increase in hope and motivation for recovery and a better future; and improved trust and acceptance of the hospital treatment they were currently receiving. The presentation will also cover the experiences of the peer workers who facilitated the groups, and the attitudes of the hospital staff towards peer support.

This abstract was presented in the Peer Support stream of the 2014 ANZAED Conference.

\section{Authors' details}

'School of Psychology, University of Western Australia, Perth, Australia.

${ }^{2}$ Eating Disorders Program, Specialised CAMHS, Child and Adolescent Health Service, Princess Margaret Hospital, Perth, Australia. ${ }^{3}$ Body Esteem Program, Perth, Australia.

Published: 24 November 2014

\footnotetext{
* Correspondence: stephanie.wade@research.uwa.edu.au

${ }^{1}$ School of Psychology, University of Western Australia, Perth, Australia
}

Full list of author information is available at the end of the article
doi:10.1186/2050-2974-2-S1-064

Cite this article as: Wade et al:: Peer support for eating disorders: a pilot open trial of peer support for children and adolescents with eating disorders. Journal of Eating Disorders 2014 2(Suppl 1):064.
Submit your next manuscript to BioMed Central and take full advantage of:

- Convenient online submission

- Thorough peer review

- No space constraints or color figure charges

- Immediate publication on acceptance

- Inclusion in PubMed, CAS, Scopus and Google Scholar

- Research which is freely available for redistribution
() Biomed Central 